\title{
New Challenges in Democratic Theory: Interview with Mark Warren*
}

\author{
Renato Francisquini**
}

Interviewer: So today is July the $22^{\text {nd }}, 2013$. We are here in Vancouver, on a very beautiful and sunny afternoon, with Professor Mark Warren, who kindly accepted to receive us in his house for an interview.

We are going to start by discussing a question related to the very nature of our work as political theorists. Professor, in a text from 1989 discussing the current state of Political Theory, you started by affirming that the subfield of Political Theory used to be misunderstood within Political Science. Many works in the area adopted, some way or another, a poor dichotomy between normative and empirical theory as if their purposes, methods and range were completely different. The behaviorist agenda reflecting a sort of new positivist form of explanation tended to oppose a speculative theory, considered part of the history field or of Human Sciences, to a hard, empirical theory that could be confirmed or refuted by observable data.

In the first half of the twentieth century, there used to be a pretension or a claim that the second way of doing theory should replace the former one.

Mark Warren: Well, you've done a nice job of summarizing. Today, the field of Political Theory is pretty exciting and well integrated into Political Science, but not too long ago that wasn't the case at all. Sometime after the World War II, Political Science began to consolidate around a view according to which the discipline could be analogous to the natural sciences, and that Political Science really needed to find its Newton or maybe even its Copernicus. This is the idea that was expressed beginning in the 1960s in the Behavioral Revolution, a revolution that continued through the 1970s,

\footnotetext{
* Mark Warren is Harold and Dorrie Merilees Chair in the Study of Democracy at the Department of Political Science of the University of British Columbia.

** Renato Francisquini is PhD candidate at the Political Science Department of the University of São Paulo. Email: rfrancisquini@usp.br.
} 
and then in another way in a formal theory that really got started in the 1970s, and that continues into this day. These scientific agendas haven't gone away, but they've been re-contextualized, I would say. And they have been re-contextualized, in part, because the discipline of Political Science is fundamentally normative. The phenomena that we call political are phenomena that are, in part, constituted by normative questions.

To quote Max Weber, he wrote in his famous essay "Politics as a Vocation" that there were really two important questions. I'm going to quote loosely because I can't remember the exact quote. But it is something to the effect of "We need to know what we should do and how we should live." These are the political questions par excellence.

Political Science remained healthy as a discipline, in part, because it continues to be normative in this sense. And the explanatory parts of the discipline, today, are nicely contextualized, at least on average, within important normative questions. The questions having to do with democracy, with representation, with political trust, with exploitation, domination, with questions of justice, questions of race, racism, questions of inclusion, exclusion. These are all, of course, the topics of Political Theory, and these topics are the topics that keep the explanatory questions - questions that are framed by these types of issues - alive and well and healthy.

But this is a fairly recent development, this understanding of Political Science and Political Theory's role within it. Political Theory as a discipline came out of the history of political thought. And in so far as it came out of the history of political thought it was the study of old and canonical texts. And so it had much more in common with the humanities than with explanatory sciences, the kind that was developing in Psychology and Economics, in particular, and, into a lesser degree, in Sociology.

Empirical Political Scientists were asking in the 1960 s and 70s why a humanistic way of understanding politics belong to the Political Sciences at all. And through the 1960s and 70s, at least in the Anglo-American world of Political Science, Political Theory was progressively marginalized. But this process also coincided with the rise of the Civil Rights Movement in the US, the rise of feminism, with the development of 
ecological and green political thinking, with questions of war and peace, with the fall of the Berlin Wall in 1989, with the progressive demise of ideologies that were alternatives to democracy.

So the world conspired, we might say, to bring the normative questions back into Political Science. And the process of marginalizing Political Theory within Political Science was, to some degree, successful and the number of Political Theory positions in Political Science declined through the late 1970s and into the 1980s. But political theorists really reinvented themselves, partly in response to criticisms from empirical political scientists, partly in response to world events of the type that I've just been mentioning. And it became through this period more issue-focused, more topical, more - you know I hate to use the term - but more relevant; it became more relevant and re-approved or newly approved the case for Political Theory within Political Science. And I think that's where we are today. The case's been made. Political Theory is focused on things that people care about, it serves as a kind of normative envelope that helps to argue for or to cast the relevance of explanatory problems.

Interviewer: So, you're arguing that theoretical research nowadays share with empirical studies the ambition to reduce the complexity of the political world in order to make it more manageable as an object of study. And this was not the case a few decades ago. We know that one important development in the subfield of Political Theory was due to the model-based theories that emerged in the mid-1900's. Can you tell us what was the role of the models of democracy and other theoretical frameworks in this new form of understanding and relating with Political Theory?

Mark Warren: The idea of models in democracy was one of the first responses to the history of political thought. The idea came from C.B. Macpherson, who was at the University of Toronto. He developed the idea and defended the idea that there were different complexes of ideas having to do with democracy that could be analytically modeled and then studied in the form of models. 
The approach was quite influential because it made the history of political thought relevant to emerging political ideals. It allowed a kind of critical focus on the history of political thought, and it enabled the history of political thought to interface with other forms of Political Science, theories of representation, theories of electoral systems, theories of elite selection, theories of complexity in governance. And it was firmly successful in drawing these bridges between Political Theory and Political Science.

My opinion, however, is that the idea of models of democracy has probably outlived its usefulness now. One of the ways in which the models were developed used the following strategy: People who think in models typically think about "a" problem. The problem of community, in the case of republicans, the problem of the lack of participation, in the case of participatory democrats, or the problem of engaged citizenship, the problem of deliberative decision making, in the case of deliberative democracy. Now, in each case models tend to be built around one kind of problem. But it is certainly the case that democratic systems, good democratic systems, have to accomplish a lot of different tasks. They need to solve problems of inclusion/exclusion, they need to form, deliberatively, collective wills that people can recognize as part of their own, that people can justify to one another. And they need to make decisions. They need to make decisions often using mechanisms such as voting.

So I think it turns out that if we look at what democratic systems need to accomplish functionally and normatively, no single model captures all of these things that need to be done. For this reason, what we should probably go back to, what we should rediscover, is the "systems thinking"; we should try to recast systems thinking in a way that is normatively adequate. That is, every time we ask about a function, we need to ask what the purpose of the function is and then we need to justify that purpose normatively. That is the link that will bring systems theory back in the conversation with normative democratic theory. And I think it will allow us to move beyond models-based departure.

Interviewer: Allow me to interrupt you here because I want to go back to this point later. So let me ask you about something else, about an issue that you have been 
working with for a long time and that has been occupying a prominent place within the subfield of Political Theory. Over the latest years, Political Theory, in general, and theories of democracy, in particular, have broadened their scope and developed sophisticated methods to understand and organize political work.

Deliberative democracy has certainly a prominent place in such quantity and quality increase. Since Habermas' critique of the decadence of the bourgeois public sphere, deliberative theory had experienced an astonishing proliferation having given birth to a diversity of approaches, several empirical research programs and other innovative institutional designs.

In part, deliberative democracy is an alternative to orthodox theories of democracy that sustained a view of society centered in the state, which used to reject the idea of common good and think of democracy as solely a method for choosing between political elites.

How does deliberative democracy represent a paradigmatic change in democratic theory? And what elements does it bring to the table that improve our understanding about politics and society?

Mark Warren: You're absolutely right. The theory of deliberative democracy came on the scene fairly quickly and robustly from a number of different sources, especially in the late 1980s and early 1990s, and was proved to be an incredibly productive research paradigm in democratic theory. It has its historical origins, of course, that are quite old, going back to Aristotle's Politics and then, in some ways, recaptured by democratic republicans like Thomas Jefferson, recast by liberals like John Stuart Mill, updated in the American context by Dewey and so on. So deliberative democracy is not new but it was newly named and enabled the rediscovery of these traditions.

Now, in part, the reason why deliberative democracy came on the scene as a model on the Political Theory research program, is related to what happened to mainstream theories of democracy, which have been colonized mostly by 
institutionalist and behavioral political scientists. They placed elections in the heart of democracy.

Deliberative democracy is not an alternative to elections, but it refocuses on a basic truth about democracy. Democracy is about changing the medium through which political conflict is conducted - from fighting through coercion and weapons to talking and voting. Democracy is a kind of medium shift with respect to political conflict.

The voting-based theories of democracy, while important - they remain important and it is impossible to think about democracy without all of these mechanisms -, pushed aside this important idea of shifting medium in the way that political conflict is conducted. And, in doing that, these theories marginalized ideas that are incredibly important to the legitimacy and viability of democracy. The development of common solutions to problems that people can recognize as their own; the giving and receiving of reasons; the attentiveness to the fact that other people have other ways of thinking about controversial political issues; the motivational force that follows from reason and reason-giving.

So deliberative democracy is able to talk about legitimacy and political judgment in a way that institutionalist and voting-focused accounts of democracy could not.

Interviewer: Do you think that the reemergence of this process of valuing the argumentative dynamic is also related to the political events that went on during the late 1970s and during the early 80s? You mentioned before the emergence of the feminist movement, for example.

Mark Warren: That's an interesting question. I think that there are a number of events that, I would say, coincided in the late 1980s and early 90 s to push this paradigm of democracy. One in the set of events were the events associated with the emergence of the New Left, those issue-focused transformations - feminism, civil rights, anti-racism and so on and so forth. Up until the fall of the Berlin Wall, these events sat side by side in the Western World with older forms of Socialism and Marxism or other essentially class-based approaches. The Cold War had tended to 
freeze conversations about democracy into the choice of either a kind of electoral representative democracy represented by the allied victors in World War II or Communism. And because this was the kind of hegemonic dichotomy, there was no real reform space for much of the New Left. And the Old Left, sided often very uncomfortably with authoritarian or quasi-authoritarian ideas, that by 1989 had proved themselves unviable. That, I would say, in post World-War-II period, but they were clearly unviable by the time the Berlin Wall fell.

Now, after the fall of the Berlin Wall, this was a challenge to the democratic Left, they were pushed to reinvent themselves and to become more politically relevant. That introduced a new sort of reformist thinking. The reformist thinking that had always had a kind of strain in Europe in revisionist Marxism, in Socialism in the German Socialist Party and so on and so forth. But now connected with the New Left in the post-1989 world. And there was a deficit of good theoretical models, and it was into that deficit that the idea of deliberative democracy stepped, pulling together strains of participatory democratic theory with big questions about justice and injustice, racism, anti-racism and so on and so forth, and packaged this into the idea that we've got to talk about political and moral questions; we need to inject normativity into the political systems that we actually have. We can't be utopian about this. To be utopian is to be regressive rather than progressive, to do nothing when you could be doing something. The medium for doing something is a combination of pressure and talk. And I think that's what propelled the idea of deliberative democracy into the position that it began to take up in the late 1990s.

Interviewer: Among the recent developments in the deliberative field of democratic theory, I'd like to highlight the rediscovery of the systemic approach that you have mentioned earlier. Basically, this perspective views democracy as a complex and differentiated political system in which different institutional mechanisms should be used to address specific problems. In this sense, distinct forms of participation vote, deliberation, protests - perform different functions within democratic societies. 
Why does the model way of thinking cannot properly address the problems of legitimacy posed by modern democracy? And in what ways does the systemic approach is capable of overcoming such difficulties?

Mark Warren: Maybe to back up a little bit...For those of us who came out of a kind of participatory radical democratic tradition, we were faced with the problem or the challenge that to be good, engaged citizens under contemporary conditions there is a very high bar. Our societies are diverse, they're complex, they're large-scale, and so some of us have been trying to imagine how strong ideals of citizenship could fit with these kinds of societies.

Some of the models that we inherited - participatory democracy in particular, but in some other ways the model of deliberative democracy - pose ideals that were very difficult to realize, at least in the general or in the abstract sense under the conditions, or within the kinds of societies that we now have and that we'll certainly have in the near future.

We could continue to think in ways that are relatively abstract and utopian and insist on strong participation wherever we can get it, a strong deliberation wherever we can get it, and that's probably a good thing to do. But I think we also need to ask how we can realize these kinds of ideals under contemporary conditions. And when we do that, we need to start thinking about divisions of labor. We need to imagine - well, imagine is what I think is in fact the case - that each citizen has a certain number of participatory resources, a certain amount of participatory resources, and really these resources don't stretch very far when you think about all the things that affect each citizen in complex, large-scale societies.

So can we think about how citizens might be able to maximize these resources? How could they direct these resources toward the areas that really count, the areas that are really important?

But to think in that way, again, is to imagine a kind of complex division of labor in which the citizens are doing one thing at one time and another thing at another time. They are counting on fellow citizens or they are counting on representatives, or they are counting on associations to look after this issue or that task. 
When you start posing those questions, you move into the area of systems. And this amounts, I think, to a rediscovery of a system's theory which actually has quite an old history that came back from Aristotle, Marx, David Easton, Talcott Parsons and so on and so forth.

We need to imagine systems, imagine democracy as a system in part because we need to think about divisions of labor among citizens and among the kinds of institutions that comprise the kinds of systems that we have today.

Interviewer: When you talk about using different arrangements to accomplish the specific functions democracy requires, you mean that, in some ways, particular arrangements are more adequate and can realize different functions. In this sense, we don't apply the same basic requirements to some mechanisms that we apply to the others. Some spheres of a deliberative system will not be very deliberative. Others, will promote deliberation, but will not do it in a very equal basis. So we accept inequalities, secrecy, lack of discussion in specific areas in order to accomplish a fair deliberative system in a broader sense. It is sometimes difficult not to mention the critics to the functionalist approach or the way it allows to much inequality in order to get a better outcome of the system as a whole. Would it be the case of establishing some desirable results beforehand and only mathematically managing political institutions to accomplish these ends? Isn't it from the nature of democratic politics that the end of the political society should be opened to citizens' self-determination? How can the systemic perspective escape from such critics?

Mark Warren: Let me answer the second question first. Systems theory, the kind that was re-imported into the American Political Science after World War II, had its origins in Talcott Parsons and his structural functionalism. The way systems theorists organized their thought - the systems theorists within this tradition - was by thinking about the kinds of functions that a society needs to accomplish in order to reproduce itself. 
Now, in posing the question that way, structural functionalist systems theories reified society. They imagined that it was an organism that has certain kinds of functions to which citizens were subordinate, agents were subordinate, institutions were subordinate and so on. And what they did in thinking this way was to generate a kind of conservative ideology. That is, societies survive, they live on, they reproduce themselves because the pieces of a society are functional for the survival of a society.

As you can see from this language, there's a kind of biological analogy here too. It is as if society is an organism. You know the circulatory does some necessary functions, the organs do other necessary sorts of things and so on and so forth. But of course this is not what a society is.

To move to a systems theory that doesn't become in effect an organic sort of ideology, we need to think of functions as normative purposes. Things need to be done because we believe they should be done and we can justify they should be done. If we inject normative questions into systems theory in that way, then it is not a problem to think about systems and functions, specializations within systems. We've normatized it, and in normatizing it, we've de-ideologized the theory. We can ask the critical questions about whether a function should in fact be a part of a system. And when we do that, I think that there's no objection, there's no ideologically normative objection to moving back toward a systems theory and systems way of thinking.

Interviewer: A democratic system faces at least two paradoxical impulses, often pushing it in opposite directions. At the same time that we claim for more inclusion, publicity and discussion, we need our institutions to get things done. The fiscal cliff in which the United States fell last year is probably a good example of how democracies can easily get into a gridlock and postpone the solutions of urgent problems, the outcomes of which can be really serious for its citizens.

You're involved with Jane Mansbridge and other leading scholars in a task force of the American Political Science Association entitled Negotiating Agreement: Getting Things Done in Democracies that have been dealing with the theoretical and practical consequences of impasse for contemporary democracies. 
Another concern of the task force is to get a deeper understanding of how institutions can address conflict and the politicians can reach agreement on controversial moral and political issues. Some authors - I would mention Diana Mutz argue that individuals are less likely to decided when exposed to different views from theirs. Would a trade-off, for instance, between inclusion and problem-solving take us back to elitist democracy? Is it possible to conciliate these two democratic masters, inclusion and deliberation, on the one side, and decision-making and problem-solving, on the other, without falling into a trade-off between the two?

Mark Warren: This is one of the most important sets of questions that we now face. Let me begin by giving a kind of democratic theory answer to this, following from a kind of systems approach.

One of the things that I have been arguing recently is that the political system really needs to do only three big things. But it has to do all of these three big things. It needs to include people, that is, to communicate their interest and their values to the political system. Secondly, it has to transform these voices, interests and values into collective will, or collective agenda. And then it needs to make decisions. Unless a system can make decisions, there's no people that is capable of acting for itself, there's no society that can solve its own problems. So democracies need to have all of these moments. And where you have one kind of function crowding out another, you also are damaging democracy.

Now, as to trade-offs. Of course, in most systems, there are trade-offs among and between these functions. But ideally we should be looking for political institutions that manage to convert inclusion into agendas and then manage to convert agendas into decisions. Some systems don't do this very well. The American system, for instance, because it is built around checks and balances - because it's essentially built as a guarantee against tyranny - is very gridlock-prone. It does a somewhat good job of inclusion, but it doesn't do a very good job of transforming those inclusions into 
agendas and then, of course, because of checks and balances, there's no strong decision point.

But there are other systems that are much better at accommodating proportional representation and parliamentary constitutional arrangements. These systems do a pretty good job of inclusion because in one sense people are represented, minority views and voices are more likely to have a voice in the collective decision-making body like a parliament. But, in other, because powers are somewhat concentrated, there are points of decision. And so the inclusions can be converted through parliamentary decisions, deliberations can be transformed into agendas, the agendas can be converted into decisions, and these decisions can then reflect back into society. Now, the countries that have done a pretty good job of making these sorts of conversions work - Denmark would be a case in point - also have many, many points of inclusion and inflection, many points of absorption, and then many points in which deliberations continue to convert these inclusions into agendas, many points of publicity and so, when decisions are finally taken, they're relatively inclusive decisions that benefit from a high degree of legitimacy because there's been a lot of processes that happened in advance of the decisions.

So, I guess what I'd say about the question of trade-offs is that there are some kinds of systems, like the American system, that generate trade-offs. But these are not necessary. They're institutionally contingent trade-offs. We could have better institutions or reform the institutions that we have so that they would work better or supplement them with different kinds of devices, and if we could do that in the right way, then the trade-offs would be much less harmful.

Interviewer: In what point is the task force right now? Are there workshops planned for the future?

Mark Warren: The task force needs to deliver a draft report on August $20^{\text {th }}$ 2013 , but the report will go through a number of revisions after the delivery. And then it will be disseminated broadly in the hopes that it will generate some publicity and 
some new research agendas, put this kind of problem on the agenda of political scientists and of political systems in the way that it probably needs to be.

Interviewer: There is another issue related to the task force that I would like to explore. It seems to me, from some events I've attended in Canada, and specially from one of the workshops promoted by APSA and UBC's Centre for the Study of Democratic Institutions (CSDI), that political scientists in North America have the concern of engaging in public debate. In the event I'm mentioning, the director of the CSDI, Professor Max Cameron, organized a meeting in which many researchers joined politicians, think-tanks and journalists to discuss practical issues related, among other things, with how real political systems can promoted the ideals that are constantly discussed by Political Theory. One thing that impressed me is the way political scientists in general and political theorists in particular engage in public debate and try to make their voices heard by the political system. This is something I don't really see happening in Brazil.

Mark Warren: The Canadian system and the US systems are different systems with different histories. The positive side of Canada, the Canadian system is still relatively young as compared to the American system and relatively in flux. So there are probably more points of entry for institutional reform in Canada. That said, Canada inherited a very old system and, in some ways, a not very good system, the British Westminster system. And it produces governments that are actually quite closed to outside influence. They tend to become relatively autocratic, relatively secretive and relatively authoritarian, and it is almost always the case that governments in Canada last a couple of elections, maybe more. And then they are pushed aside by relatively strong forces of civil society as they begin to lose touch.

So we do have a tradition of political debate and a tradition of intellectual influence. It doesn't interface very well with the system of government that we have. But the US system is... you know, each system has its own pathologies. The US system 
is pluralistic, yet, it favors well-organized interests. Its pluralism does leave it open to a relatively well-organized intellectual influence. In Washington the influence tends to work through think-tanks. And this is something that the US system has that the Canadian system does not - Brookings and the Carnegie and the Indo-American Foundation and the American Enterprise Institute on the conservative side and so on. So there are conduits, or points of translations, institutionalized points of translation between academic thinking in Political Science and at least some of the things that penetrate government and governance in the US.

That said, that is only part of the picture and the gridlock-prone nature of the system can keep most good ideas from having much of an impact on policy for most of the time.

Interviewer: Another issue that called my attention in the workshop, now thinking more about the theoretical questions elaborated, is that some of the problems highlighted there were, in the last 10 or 15 years, carefully debated within deliberative theory. I would mention, for example, the problem of self-interest and bias in negotiation, the question of trust, and the controversy between secrecy and publicity: these were all part of the deliberativists' agenda, and deliberative theory presented a very strong defense of publicity, of public deliberation etc. Do you think the concerns brought up by the workshop as well as the tentative responses being elaborated represent a sort of a departure from discursive ways of dealing with political conflict?

Mark Warren: The task force drew pretty heavily on deliberative democratic theory. And it did so, in part, because, I think, of a warranted faith that if things are going to get done in a democracy, they're going to be done in part because people are able to talk, to bargain, to appreciate where other people are coming from, to compromise. Now, all of these said, one weakness of deliberative democratic theory this is again a weakness of models-based thinking - is that it focuses primarily on the second task of the three tasks that I've mentioned that are necessary for the political 
system to count as democratic, that is inclusion, collective will formation and decisionmaking.

Deliberative democratic theory hasn't added much to the theory of decisionmaking and, for that reason, has not counted as a strong response to problems of gridlock, which tend to occur at the points of decision-making. But, anyway, we really hope that the task force will contextualize the contributions of deliberative democratic theory within problems of decision-making and, in this way, help to upgrade and further develop the theory of deliberative democracy.

Interviewer: Now moving back to practical concerns related to the theoretical discussion we're doing here, I would like to discuss about some recent events we have been following in contemporary democracies. Over the last two or three years we have been seeing citizens all over the world discontent with the isolation of the political system from their control, claiming for greater participation in collective decisions. Many countries, by initiative of the government, or through direct involvement of civil society organizations, have been developing innovative forms of participatory governance. Sometimes, these arrangements complement the work of traditional political institutions; sometimes, they control or compete with traditional forms of democratic organization. From the perspective of the systemic approach, what would be the functions of these new institutions, or what are the functions these new institutions can perform in furthering democratization? And what tasks are they incapable of accomplishing?

Mark Warren: We're seeing quite a political revolution in the broad area of participatory governance. To some degree, I think the big picture in participatory governance is that the participation is an elite response to societies that have become stronger and stronger, and more self-confident, and more capable of generating advocacy, pressure, veto points and so on. 
Many governments responded with new forms of inclusion, new forms of participation. The incentives are pretty often the incentives to avoid gridlock and veto. But one of the consequences is that these kinds of incentives can produce a lot of innovation in participatory governance.

One of the most interesting developments over the last couple of decades is that a lot of the innovations in participatory governance have come not through electoral democracy, but rather, through administration. Governance issues, beginning in Europe and the US in the 1960s and in Vancouver and Toronto, and Australia beginning with urban planning, moving into problems of land use and environmental areas in the late 1970s and early 1980s, and then extending to other areas of governance in the 1990s.

Very often - to come back to the systems question - the kinds of participatory innovations that we've seen are innovations that tend to happen within relatively established political systems, where there's some capacity for uptake decision-making in the administration. So it is not that participatory innovations are weak. But they are more successful where they are complemented, shall we say, by civil society organization, on one hand, and administrative capacity, established state administrative capacity, on the other. And that's, I think, something we're going to see more and more of as political systems evolve.

Interviewer: You're currently engaged in an initiative that intends to provide a platform for researchers and practitioners all over the world to exchange experiences and compare the ability of participatory arrangements to further democratization. Can you tell us a little bit about Participedia?

Mark Warren: Participedia is a response to - and if we think about this from the standpoint of Political Science - an academic problem, which is that in Political Science we know a lot about electoral systems, we know about executive branch agencies, because these things have been around for a long time. But the new forms of participation, these participatory innovations that we've seen develop over the last few decades, and especially of over the last decade, the landscape is quite new and we 
don't really know what it looks like. We have lots of case studies. We have anecdotes and so on and so forth, but we don't have good maps of all of the participatory innovations. And just to give you an idea of the variety, there are probably around a hundred and fifty - maybe two hundred, maybe more - named and branded kinds of processes: citizens' juries and citizens' assemblies, deliberative polls and Socrates' Cafés.

Participedia is an attempt to have a structured platform that would begin to map this very pluralistic and varied domain of participatory governance. And to do so in a way that is more powerful than even a good team of Political Science researchers could bring to this problem. It consists of an Internet platform that asks for a structured article on a case, and then, behind that, there are a lot of data to be inserted into the system. And when the platform is fully built, we will be getting a hundred and fifty or two hundred data points associated with every case. And these data points will help us to both sort and explain the cases in the different types, but also to explain why some kinds of processes are good for some types of issues and good for accomplishing some kinds of goals under the conditions under which it's operating. That is, we hope that Participedia will begin to give us a database to do good comparative research on participatory innovations, as we can do on more traditional political institutions.

Interviewer: I would say that the area of Political Science is the one within social sciences that deals more closely with controversial and unstable issues related to the State and distribution of power, social justice, etc. In a word, we are constantly mobilized by society's changing understanding of itself; countries as distinct as the USA and Turkey, Brazil and Spain have been facing an increase in citizens' dissatisfaction with the political order and its outcomes. The dissatisfaction movements caught by surprise most of us, citizens and political scientists. In a very speculative exercise, could you, please, try to list the questions related the recent events you think are and will be motivating political theorists in the years to come? 
Mark Warren: I think that there are two forces at work that are producing these developments. One is the development of new, more confident, better organized citizens. The development of advocacy capacities within civil society; the learning about how to advocate, how to organize across countries, these are quite important factors.

The other thing I would say is that we're seeing these movements in countries where, although they are mostly electoral democracies, are not very good electoral democracies, they're not highly responsive. For one thing there is a perception of relatively high levels of corruption. There's also a certain amount of elite closure. So I think the combination of these two things, the post modernization of society and the increasing confidence of civil society combined with relatively rigid, not very responsive governments. That's what seems to be producing the protests concomitantly from Quebec, which in Canada used to be a relatively corrupt province, to Spain, to Greece, to Turkey, to Brazil.

Interviewer: Do you think there is a reaction in these movements against the secrecy in political affairs and, somehow related to this, against the control that the markets and big corporations have over politics?

Mark Warren: The movements are certainly calling for new sorts of inclusion and responsiveness, and it surely starts with the perception of the degree that powerful economic actors develop alignments with political elites, which is a hazard in any market-focused capital system; and to the extent that that occurs and that the population realizes that decision making processes are being co-opted by these actors that are, by definition, unresponsive, the movements, of course, are targeting that type of alignment.

Interviewer: These movements have somewhat surprised all of us. Even politicians who must react quite immediately to such events are not being able to react adequately, what to say about Political Science. Do you see any reactions within 
our field to these movements and to these new forms of protests that are related to social media and new forms of communication?

Mark Warren: Political science is always slow to react because it's primarily an academic profession, and only secondarily a political profession. It takes time to think, to explain, to deal with studies, to figure out what's going on. It's more the job of public intellectuals, some of them descendant from the academic field, to give on-thespot interpretations. Now, that said, from a Political Science standpoint, many of these protests are not that surprising. We have good social movement theory, good structural theories dealing with the pressure points within the political systems. And, again to some degree, these theories are good in a generic way in trying to explain what's going on.

Of course, no general theory is going to be able to explain the particular triggers for these movements. The political scientists would not have been able to predict that an increase in bus fares would set off such important protests, or that a particular proposal to destroy a public park in Turkey would set off demonstrations there. But the underline structural tensions, that's something political scientists are good at thinking about.

I think there will be more and more academic reactions. One of the things that is probably new about these protests, these developments, is that there is quite a bit of learning across the movements. And a learning that certainly has been enabled by the Internet, also enabled by more mobility, more globalization, more movement of students from one country to another. These are all relatively new things, and that's one of the interesting effects of not just the new technologies but more generally of globalization. I think political scientists and other scholars will sooner or later incorporate these variables and try to produce relevant research of these movements. 